\title{
Factors associated with the high medication regimen complexity index in pediatric patients with chronic renal disease
}

\begin{abstract}
Amanda Maria de PAIVA ${ }^{1}$, Lívia Pena SILVEIRA² ${ }^{(D}$, Ronara Camila de Souza GROIA-VELOSO ${ }^{(D)}$, Isabela Barros Diniz RAGGI ${ }^{1}$ (D), Máyra Rodrigues FERNANDES ${ }^{1}$ D, Patrícia Gambarelli de ARAÚJO² $\mathbb{D}$, Maria das Dores Graciano SILVA² $\mathbb{D}$, Clarice CHEMELLO²

${ }^{1}$ Residência Multiprofissional em Cuidado Humanizado da Criança e do Adolescente, da Universidade Federal de Minas Gerais, Belo Horizonte, MG - Brasil, ${ }^{2}$ Hospital das Clínicas da Universidade Federal de Minas Gerais, Belo Horizonte, MG - Brasil
\end{abstract}

Corresponding author: Paiva AM, amandampaiva@outlook.com

Submitted: 24-07-2020 Resubmitted: 13-10-2020 Accepted: 22-10-2020

Peer review: blind reviewers

\begin{abstract}
Objective: To determine the factors associated with the high medication regimen complexity in pediatric patients with chronic kidney disease. Methods: An observational, cross-sectional, descriptive and analytical study was conducted with patients treated at a multiprofessional outpatient clinic of a public teaching hospital. Data were collected from July to September 2019 from the medical record and pharmacotherapeutic follow-up form. The medication regimen complexity was the dependent variable and was assessed by the Medication Regimen Complexity Index. the independent variables were sex, age, number of diseases, number of medications, adherence to treatment and access to health services. The complexity was considered high when the the Medication Regimen Complexity Index was greater than 13.5 points. The association between the occurrence of high complexity of pharmacotherapy and the independent variables was performed using Pearson's chi-square test and Fisher's exact test. For univariate and multivariate analysis, the magnitude of the association was expressed by the odds ratio with a 95\% confidence interval. Results: All patients treated during the study period were included in the study $(n=31) .67 .7 \%$ of patients $(n=21)$ used at least four drugs, the same percentage presented complexity of high pharmacotherapy, being associated with the number of drugs used $(p<0.001)$. The class of drugs, plus drugs that do not act on the cardiovascular system, 30\% ( $n=30)$. The most used medication by patients was sodium bicarbonate $(n=22 ; 70 \%)$. Conclusions: The high medication regimen complexity was associated with the number of drugs used and was observed in most patients studied, highlighting the importance of assessing the ICFT in children to optimize pharmacotherapy and, consequently, pediatric patient safety.
\end{abstract}

Keywords: chronic kidney disease, pharmacological treatment, pediatrics, pharmaceutical care, drug utilization.

\section{Fatores associados à alta complexidade da farmacoterapia de pacientes pediátricos com doença renal crônica}

\begin{abstract}
Resumo
Objetivo: Analisar os fatores associados a alta complexidade da terapia em pacientes pediátricos com doença renal crônica. Métodos: Estudo transversal, realizado com pacientes atendidos em um ambulatório multiprofissional de um hospital público de ensino. Todos os pacientes atendidos nos meses de julho a setembro de 2019 foram incluídos no estudo e os dados foram coletados a partir do prontuário e formulário de acompanhamento farmacoterapêutico. A variável dependente do estudo foi a complexidade da farmacoterapia, mensurada pelo Índice de Complexidade da Farmacoterapia, e as variáveis independentes foram sexo, idade, número de doenças, número de medicamentos, adesão ao tratamento e acesso aos serviços de saúde. A complexidade foi considerada alta quando o Índice de Complexidade da Farmacoterapia (ICFT) foi maior que 13,5 pontos. A associação entre a ocorrência de alta complexidade da farmacoterapia e as variáveis independentes foi realizada utilizando-se o teste de qui-quadrado de Pearson e teste exato de Fisher. Para análise univariada e multivariada, a magnitude da associação foi expressa pelo odds ratio com intervalo de confiança de $95 \%$. Resultados: Todos os pacientes atendidos no período estudado, foram incluídos no estudo ( $n=31) .67,7 \%$ dos pacientes $(n=21)$ usava pelo menos quatro medicamentos e a mesma porcentagem apresentou complexidade da farmacoterapia alta, sendo associada ao número de medicamentos utilizados $(p<0,001)$. No que se refere à classe de medicamentos, a mais utilizada foi a de medicamentos que atuam no sistema cardiovascular, $30 \%(n=30)$. O medicamento mais utilizado pelos pacientes foi bicarbonato de sódio ( $n=22 ; 70 \%)$. Conclusão: A alta complexidade da farmacoterapia apresentou associação direta com o número de medicamentos utilizados. A maioria dos pacientes incluídos no estudo apresentou alta complexidade da farmacoterapia, sugerindo a importância da avaliação do ICFT em crianças para otimizar o tratamento e, consequentemente, melhorar a segurança do paciente pediátrico.
\end{abstract}

Palavras-chave: insuficiência renal crônica, tratamento farmacológico, pediatria, assistência farmacêutica, uso de medicamentos. 


\section{Introduction}

The prevalence of chronic diseases in the pediatric population has been increasing around the world. In the United States, approximately $25 \%$ of the population from 0 to 17 years old has at least one chronic disease. ${ }^{1}$ In Brazil, nearly $9 \%$ of the children from 0 to 5 years old; $10 \%$ of those from 6 to 13 years old, and $11 \%$ of those from 14 to 19 years old have a chronic disease. Although the occurrence of chronic diseases in pediatric is lower incidence in comparison with the adult population, the literature highlights conditions in which children and adolescents use polypharmacy, and chronic kidney disease (CKD) is one of them. ${ }^{2}$

CKD is characterized by changes affecting the renal structure and function or by a glomerular filtration rate lower than $60 \mathrm{~mL} / \mathrm{min} / 1.73$ $\mathrm{m}^{2}$, lasting more than three months. ${ }^{3}$ In pediatric patients, prevalence ranges from 55 to $75 / 1,000,000$ worldwide. ${ }^{4}$ The mortality rate of dialysis patients from 0 to 18 years old is $30 \%$ to $150 \%$ higher than in the general pediatric population, and the life expectancy of dialysis children from 0 to 14 years old is approximately 20 years. ${ }^{5}$ The pharmacological treatment of CKD involves medications of different classes to control comorbidities, such as antihypertensives, erythropoiesis-stimulating agents, vitamins and mineral supplementation, among others, sometimes requiring polypharmacy. ${ }^{2,6}$

Polypharmacy is strongly related to the occurrence of negative outcomes in the use of medications and to the increased in complexity of pharmacotherapy. ${ }^{7,8}$ Pharmacotherapy complexity, in turn, is signaled in various research studies as a factor for nonadherence to treatment, hospitalization, and rehospitalization, based on characteristics of the therapeutic regimen (such as number of medications prescribed, dose, frequency) and on the need of specific instructions (how to crush, break, or dilute pills). ${ }^{8,9}$ These guidelines are common in Pediatrics due to the lack of preparation of medications for that population, requiring fractioning or dilution of pills and capsules to individualize doses, resulting in increased pharmacotherapy complexity. ${ }^{10}$ The determination of pharmacotherapy complexity based on the Medication Regimen Complexity Index (MRCl), developed by George et al in 2004, ${ }^{11}$ validated and translated into Brazilian Portuguese in 2007 by Melchiors et al, allows for the identification of the factors that most contribute to the administration difficulty of these medications and which therefore directly or indirectly influence adherence to treatment. In patients with CKD, adherence to treatment is essential to control the disease and its comorbidities. ${ }^{6,8,12}$ This study aims to analyze the high complexity of pharmacotherapy and factors associated to pediatric patients in a multidisciplinary outpatient clinic for chronic kidney disease in a teaching hospital.

\section{Methods}

\section{Place and population}

This is a cross-sectional study carried out at the pediatric outpatient clinic for CKD of a public, general, and large teaching hospital located in Belo Horizonte/MG. This hospital provides care to patients with diseases of medium and high complexity and performs training, research, and care activities. The outpatient clinic for CKD sees patients from 0 to 17 years, 11 months and 29 days old, with a multi-professional team composed of physicians, nurses, pharmacists, nutritionists, and psychologists. The pediatric outpatient clinic for CKD is one of the practice settings of the Multidisciplinary Residency in Humanized Care for Children and
Adolescents, which started operating in March 2016 and includes Pharmacy, Nutrition, and Dentistry professionals.

The resident pharmacists work at the Clinical Pharmacy Unit of the Hospital Pharmacy Sector, which provides clinical services of pharmacotherapy management, analysis of medical prescription, pharmaceutical instructions to patients and caregivers, support to the multi-professional team, and health training, among others, aiming at a safe and rational use of medications for inpatients and outpatients. In the pediatric outpatient clinic for CKD, the pharmacotherapeutic follow-up is carried out, in which pharmacotherapy is managed During the appointment, the pharmacist reviews the pharmacotherapy, identifies and seeks solutions to the problems related to the use of medications, and applies instruments to assess pharmacotherapy complexity and patients' adherence to the treatment. The patients are continuously followed-up until they are discharged from the service. The instrument assessing adherence is employed only in the first appointment, and the $\mathrm{MRCl}$ is calculated whenever there are changes in pharmacotherapy. The data of this study were collected from secondary sources after the first pharmacotherapeutic followup appointment.

The sample included all the patients seen by the pharmacist at the outpatient clinic for CKD aged from 0 to 17 years, 11 months and 29 days old, who used at least one medication. The patients were referred by the multi-professional team.. All the patients followedup in this service from July to September 2019 were included in this study, with no loss.

\section{Data collection}

The pharmaceutical appointments were carried out by two pharmacists, one tutor pharmacist and one resident pharmacist of the Residency Program in Humanized Care for Children and Adolescents. One pharmacist performed all the care and the other applied the adherence questionnaire to reduce socialdesirability bias. ${ }^{13}$ At the end of the appointments, data was collected from the patient's record and the pharmacotherapeutic follow-up instrument was filled out during the pharmaceutical appointments, i.e., the study data are secondary.

This follow-up instrument was developed by the pharmacists at the outpatient clinic and contained information regarding the patient's medical history and use of medications.

\section{Dependent variable: Medication Regimen Complexity Index}

Pharmacotherapy complexity, dependent variable of the study, was assessed using the $\mathrm{MRCl}$ instrument, the only instrument validated in Brazilian Portuguese that measures pharmacotherapy complexity based on the analysis of medical prescriptions. The $\mathrm{MRCl}$ is divided into three sections: $A, B$, and C. Section A corresponds to information about the pharmaceutical forms of the medications; Section $B$, to information about frequencies of doses; and Section C, to additional information, such as use of medications with food or variable doses along the day. The total value of the index is obtained from the sum of the points (scores) of the three sections. ${ }^{8}$ A cutoff point was adopted for the adult population to characterize complexity as high or low, as suggested by Ferreira, Galato and Melo, 2015: an $\mathrm{MRCl}$ of up to 4.5 is regarded as low, and over 13.5, as high. ${ }^{14}$ For this study, these cutoff points were extrapolated for the pediatric population, as a cutoff point for this age group was not identified in the literature. 


\section{Independent variables}

The study independent variables were gender, age, exclusive access to the public health service, person responsible for medication administration and their level of education, number and classification of the main diagnoses related to CKD of the patient according to the International Classification of Diseases (ICD-11). In addition, the following were also included as study variables: medications used by the patients according to the second level (therapeutic) and fourth level (chemical) of the World Health Organization's Anatomical Therapeutic Chemical (ATC) Classification, in addition to the number of medications used by the patients.

Adherence to treatment was also an independent variable of the study and was assessed using the Measurement of Adherence to Treatment (MAT), which was answered by the family member responsible for the administration of the medications. The MAT is a questionnaire composed of seven items that assess the person's behavior regarding the daily use of medications. The answers correspond to a Likert scale with the following scores: 1 for always, 2 for almost always, 3 for frequently, 4 for sometimes, 5 for rarely, and 6 for never. The result was obtained by summing the answer's values and dividing them by the number of questions. Values equal to or higher than 5 were considered adherent. ${ }^{15}$

Off label use was also a variable studied and defined as a lack of specification in the package insert for children and adolescents regardless of age group. The Brazilian classification was based on information in the package insert of each product by checking the Electronic Medications Compendium of the Brazilian Health Surveillance Agency, available at: http://www.anvisa.gov.br.

\section{Statistical analysis}

Data was typed on Epidata, version $3.1^{\circ}$ and analyzed in the SPSS software, version $21.0^{\circ}$. The quantitative variables were described based on median and interquartile range (IQR), and the categorical ones were expressed by absolute ( $\mathrm{n}$ ) and relative (\%) frequencies. The association between high pharmacotherapy complexity and the independent variables was carried out by means of univariate analysis using Pearson's chi-square test. In Fisher's exact test, the independent variables that obtained a $p$-value $\leq 0.20$ in the univariate analysis were included in the logistic regression model for multivariate analysis. The variables that maintained a p-value $<$ 0.05 remained in the final model. For univariate and multivariate analyses, the magnitude of the association was expressed by the Odds Ratio (OR) with a 95\% Confidence Interval (Cl).

The likelihood ratio test was used to compare the models. The adequacy of the final models was assessed by the Hosmer-Lemeshow test. ${ }^{16}$ Statistical significance was considered when $p<0.05$.

\section{Ethical considerations}

This paper was approved by the Research Ethics Committee of the Federal University of Minas Gerais, under number 80169717.4.0000.5149.

\section{Results}

All the patients followed-up by the clinical pharmacy service from July to September 2019 at the pediatric outpatient clinic for CKD and who used at least one medication were included in the study ( $n=31), 24$ (77.4\%) being males. The median age was eight years old $(I Q R=8)$. Regarding the number of clinical conditions, the median was two (IQR=2). Regarding CKD stage, $45.2 \%$ of the patients $(n=14)$ were at stage 3 .

Regarding access to health services, $87.1 \%$ of the patients $(n=27)$ are exclusively assisted by the Unified Health System. The mothers were identified as responsible for managing the medications in $87.1 \%$ of the patients $(n=27)$, and $42.2 \%$ of them $(n=14)$ have completed high school.

The median of the number of medications used was four (IQR=3) and $67.7 \%$ of the patients $(n=21)$ used at least four medications; the lowest number of medications used was 1 and the highest, 10. Of the total of patients studied, $67.7 \%(n=21)$ presented high pharmacotherapy complexity. The maximum value obtained was 36 in two patients in treatment with 7 and 8 medications, and the minimum value was 6 in two patients in treatment with one and two medications. Section B was the one that most contributed to the increase in the index score, with median of 7.5 points (IQR=6). Regarding adherence to treatment, 21 patients $(67.7 \%)$ presented adherence to pharmacotherapy. A more detailed description of the study population is included in Table 1.

Table 1. Sociodemographic, clinical, and pharmacotherapeutic characteristics of the 31 patients assisted at the multidisciplinary pediatric outpatient clinic for CKD of a teaching hospital from July to September 2019. Belo Horizonte/MG.

\begin{tabular}{|c|c|c|}
\hline \multirow{2}{*}{ Variable } & \multicolumn{2}{|c|}{ Frequency } \\
\hline & $\mathrm{n}$ & $\%$ \\
\hline \multicolumn{3}{|c|}{ SOCIODEMOGRAPHIC } \\
\hline \multicolumn{3}{|c|}{ Gender } \\
\hline Male & 24 & 77.4 \\
\hline Female & 7 & 22.6 \\
\hline \multicolumn{3}{|c|}{ Age (years old) } \\
\hline$\geq 8$ & 18 & 58.1 \\
\hline$<8$ & 13 & 41.9 \\
\hline \multicolumn{3}{|l|}{ CLINICAL } \\
\hline \multicolumn{3}{|c|}{ Number of diseases related to CKD } \\
\hline$\geq 2$ & 17 & 54.8 \\
\hline$<2$ & 14 & 45.2 \\
\hline \multicolumn{3}{|c|}{$\begin{array}{l}\text { PHARMACOTHERAPY } \\
\text { Number of medications }\end{array}$} \\
\hline$\geq 4$ & 21 & 67.7 \\
\hline$<4$ & 10 & 32.3 \\
\hline \multicolumn{3}{|l|}{ TOTAL MRCI } \\
\hline$\geq 13.5$ & 21 & 67.7 \\
\hline$<13.5$ & 10 & 32.3 \\
\hline \multicolumn{3}{|l|}{ MRCIA } \\
\hline$\geq 6$ & 14 & 45.2 \\
\hline$<6$ & 17 & 54.8 \\
\hline \multicolumn{3}{|l|}{ MRCIB } \\
\hline$\geq 7.7$ & 14 & 45.2 \\
\hline$<7.7$ & 17 & 54.8 \\
\hline \multicolumn{3}{|l|}{ MRCIC } \\
\hline$\geq 3$ & 15 & 48.4 \\
\hline$<3$ & 16 & 51.6 \\
\hline \multicolumn{3}{|l|}{ MAT } \\
\hline Adherent & 21 & 67.7 \\
\hline Non-adherent & 10 & 32.3 \\
\hline
\end{tabular}

Key: $\mathrm{MRCl}$ - Medication Regimen Complexity Index; MRCIA - Medication Regimen Complexity Index part A; MRCIB - Medication Regimen Complexity Index part B; MRCIC - Medication Regimen Complexity Index part C; MAT - Measurement of Adherence to Treatment 
The diagnoses of probable causes for CKD that presented frequencies higher than 1 are described in Table $\mathbf{2}$. The most frequent are hydronephrosis with $n=12(26.7 \%)$ and congenital vesico-urethral-renal reflux with $n=8(17.7 \%)$.

Regarding the medications used by the patients, those that presented a frequency higher than one and that are included in the World Health Organization's Anatomical Therapeutic Chemical
Classification are described in Table 3. It was identified that 10 of the 38 different medications used by the patients were off label, and the most used one was bicarbonate. Regarding the class of medications, the most used were medications for the cardiovascular system, $30 \%(n=30)$. The medication most used by the patients was sodium bicarbonate $(n=22 ; 70 \%)$

Table 2. International Classification of Diseases (ICD-11) of the main diagnoses of the 31 patients assisted at the multidisciplinary pediatric outpatient clinic for CKD of a teaching hospital from July to September 2019. Belo Horizonte/MG.

\begin{tabular}{llll}
\hline ICD Classification & $\mathbf{N}$ & $\mathbf{\%}$ \\
\hline BA00.0 & Combined diastolic and systolic hypertension & $\mathbf{2}$ & $\mathbf{4 . 4}$ \\
\hline BA00.0 & Hypertension & 2 & 4.4 \\
GB41 & Nephrotic syndrome & $\mathbf{2}$ & $\mathbf{4 . 4}$ \\
\hline GB56 & Obstructive or reflux nephropathy & $\mathbf{1 2}$ & $\mathbf{2 6 . 7}$ \\
\hline GB56.4 & Other or unspecified hydronephrosis - Hydronephrosis & 12 & 26.7 \\
GB90.Y & Other specified renal tubular function disorders & $\mathbf{2}$ & $\mathbf{4 . 4}$ \\
GB90.Y\&XA7156 & Megaureter & 2 & 4.4 \\
GC01 & Other bladder disorders & $\mathbf{4}$ & $\mathbf{8 . 8}$ \\
GC01.4 & Neuromuscular dysfunction of the bladder, not elsewhere classified - Neurogenic bladder & 4 & 8.8 \\
LB30 & Structural developmental anomalies of the kidneys & $\mathbf{2 6 . 7}$ \\
LB30.0Y & Other specified renal agenesis or other reduction defects of kidney - Single kidney and Renal hypoplasia & 6 & 13.3 \\
LB30.1 & Renal dysplasia & 4 & 8.8 \\
LB30.9 & Multicystic kidney & 2 & 4.4 \\
LB31 & Structural developmental anomalies of the urinary tract & $\mathbf{1 1}$ & $\mathbf{2 4 . 4}$ \\
LB31.2 & Fetal lower urinary tract obstruction - Posterior urethral valve & 3 & 6.7 \\
LB31.D & Congenital vesico-urethral-renal reflux & 8 & 17.7 \\
& & TOTAL & $\mathbf{4 5}$ \\
\hline
\end{tabular}

Table 3. Anatomical Therapeutic Chemical Classification of the medications used by the 31 patients assisted by the multidisciplinary pediatric outpatient clinic for CKD of a teaching hospital from July to September 2019. Belo Horizonte/MG.

\begin{tabular}{|c|c|c|c|}
\hline \multirow{2}{*}{\multicolumn{2}{|c|}{$\begin{array}{l}\text { ATC classification } \quad \mathrm{N} \\
\text { Feeding tract and metabolism }\end{array}$}} & \multicolumn{2}{|l|}{$\%$} \\
\hline & & 14 & 14 \\
\hline$\underline{\mathrm{A} 06}$ & Drugs for constipation & 2 & 2 \\
\hline$\overline{A 06} A D$ & Osmotically acting laxatives - Polyethylene glycol & 2 & 2 \\
\hline A11 & Vitamines & 12 & 12 \\
\hline$\overline{\mathrm{A} 11 \mathrm{CC}}$ & $\overline{\text { Vitamin D }}$ and analogues - Vitamin D and Calcitriol & 12 & 12 \\
\hline \multicolumn{2}{|c|}{ Hematopoietic System } & 14 & 14 \\
\hline B03 & B03 Antianemic preparations & 14 & 14 \\
\hline$\overline{B 03 A A}$ & Iron bivalent, oral preparations - Ferrous Sulphate & 11 & 11 \\
\hline B03XA & Other antianemic preparations - Erythropoietin & 3 & 3 \\
\hline \multicolumn{2}{|c|}{ Cardiovascular System } & 30 & 30 \\
\hline$\underline{\mathrm{CO} 3}$ & Diuretics & 8 & 8 \\
\hline$\overline{\mathrm{CO}} \mathrm{CA}$ & Simple Sulfonamides - Furosemide & 8 & 8 \\
\hline$\underline{\mathrm{CO}}$ & Calcium Channel Blockers & 7 & 7 \\
\hline$\overline{\mathrm{CO}} \mathrm{CA}$ & $\overline{\text { Dihydropyridine derivatives }- \text { Amlodipine }}$ & 7 & 7 \\
\hline$\underline{\mathrm{COg}}$ & Agents acting on the Renin-Angiotensin System & 15 & 15 \\
\hline CO9AA & Renin-Angiotensin System Inhibitors - Enalapril & 15 & 15 \\
\hline \multicolumn{2}{|c|}{ Genitourinary System } & 4 & 4 \\
\hline G04 & Urological & 4 & 4 \\
\hline$\overline{\mathrm{G} 04 \mathrm{BD}}$ & Drugs for urinary frequency and incontinence - Oxybutinyn & 4 & 4 \\
\hline \multicolumn{2}{|c|}{ Anti-infectives for systemic use } & 15 & 15 \\
\hline$\underline{\mathrm{J} 01}$ & Antibacterials for systemic use & 15 & 15 \\
\hline J01DB & First-generation cephalosporins - Cephalexin & 2 & 2 \\
\hline J01EE & Combinations of sulfonamides and trimethoprim & 10 & 10 \\
\hline J01XE & Nitrofuran derivatives - Nitrofurantoin & 3 & 3 \\
\hline \multicolumn{2}{|c|}{ Musculoskeletal System } & 5 & 5 \\
\hline M04 & Antigout preparations & 5 & 5 \\
\hline$\overline{\mathrm{M} 04 \mathrm{AA}}$ & $\overline{\text { Preparations inhibiting uric acid production - Allopurinol }}$ & 5 & 5 \\
\hline Others & & 18 & 18 \\
\hline V03 & All the other therapeutic products & 18 & 18 \\
\hline \multirow[t]{2}{*}{$\overline{\mathrm{VOSAE}}$} & Drugs for treatment of hyperkalemia and hyperphosphatemia - Calcium Acetate and Calcium Carbonate & 18 & 18 \\
\hline & & TOTAL & 100 \\
\hline
\end{tabular}


In the univariate analysis, the variables that were associated to high pharmacotherapy complexity were number of diseases and medications. The number of medications $(p<0.001)$ variable remained in the final model, as shown in Table 4.

Table 4. Univariate and multivariate analyses of the factors associated to high pharmacotherapy complexity of the patients assisted at a multidisciplinary outpatient clinic of Pediatric Nephrology in a teaching hospital in Belo Horizonte, MG.

\begin{tabular}{|c|c|c|c|c|c|c|}
\hline \multirow[t]{3}{*}{ Description } & \multicolumn{2}{|c|}{ High Pharmacotherapy Complexity } & \multicolumn{2}{|c|}{ Univariate analysis } & \multicolumn{2}{|c|}{ Multivariate analysis } \\
\hline & Fre & & \multirow[b]{2}{*}{ OR (95\% Cl) } & \multirow[b]{2}{*}{$p$-value } & \multirow[b]{2}{*}{ OR $(95 \% \mathrm{CI})$} & \multirow[b]{2}{*}{ p-value } \\
\hline & Yes & No & & & & \\
\hline \multicolumn{7}{|l|}{ Sociodemographic } \\
\hline \multicolumn{7}{|l|}{ Gender } \\
\hline Male & $16(66.7 \%)$ & $8(33.3 \%)$ & $0.800(0.126-5.070)$ & 1.000 & - & - \\
\hline Female & $5(71.4 \%)$ & $2(28.6 \%)$ & & - & & \\
\hline \multicolumn{7}{|l|}{ Age $\geq 8$ years old } \\
\hline Yes & $13(72.2 \%)$ & $5(27.8 \%)$ & $1.625(0.355-7.434)$ & 0.701 & - & - \\
\hline No & $8(61.5 \%)$ & $5(35.8 \%)$ & & & & \\
\hline \multicolumn{7}{|l|}{ Clinical } \\
\hline \multicolumn{7}{|c|}{ Number of diseases $\geq 2$} \\
\hline Yes & $9(52.9 \%)$ & $8(47.1 \%)$ & $0.188(0.905-1.105)$ & 0.068 & $0.198(0.760-1.341)$ & 0.135 \\
\hline No & $12(85.7 \%)$ & $2(14.3 \%)$ & & & & \\
\hline \multicolumn{7}{|c|}{ Access only to the public health service } \\
\hline Yes & $18(66.7 \%)$ & $9(33.3 \%)$ & $0.667(0.060-7.352)$ & 1.000 & - & - \\
\hline No & $3(75 \%)$ & $1(25 \%)$ & & & & \\
\hline \multicolumn{7}{|c|}{ Pharmacotherapeutic } \\
\hline \multicolumn{7}{|c|}{ Number of medications $\geq 4$} \\
\hline Yes & $19(90.5 \%)$ & $2(9.5 \%)$ & $38.000(4.530-318.784)$ & 0.000 & $37.458(4.680-315.543)$ & 0.000 \\
\hline No & $2(20.0 \%)$ & $8(80.0 \%)$ & 1 & - & & \\
\hline \multicolumn{7}{|c|}{ Adherence to treatment } \\
\hline Yes & $15(71.4 \%)$ & $6(28.6 \%)$ & $1.667(0.343-8.093)$ & 0.685 & - & - \\
\hline No & $6(60 \%)$ & $4(40 \%)$ & 1 & - & & \\
\hline
\end{tabular}

Key: OR - Odds Ratio

\section{Discussion}

The importance of assessing the pharmacotherapy complexity of pediatric patients is mainly due to the particularities of this population, requiring individualization of doses according to age or weight, and demanding, for example, transformation of pharmaceutical forms to adequate their use. ${ }^{17,18}$ To date, no studies have been found in the literature assessing pharmacotherapy complexity in children with CKD, which makes it difficult to compare results and confirms the importance of studies to promote a more qualified pharmacotherapy and directed to the profile of these patients.

Most of the patients presented a high $\mathrm{MRCl}$, which can be justified by the complexity of CKD, which requires treatment with multiple medications administered several times a day. ${ }^{12}$ The aspects analyzed in Sections $\mathrm{A}$ and $\mathrm{B}$ of the $\mathrm{MRCl}$ contribute to increase it. The treatment for CKD aims to control the comorbidities resulting from the disease progression, acting in the control of systemic arterial hypertension, maintenance of erythropoiesis, and metabolites imbalances, such as dyslipidemia, hyperuricemia, and acidosis, which corroborates with the international guideline, aiming at a reduction in disease progression and mortality. ${ }^{3} \mathrm{t}$ is important to note that the outpatient clinic under study belongs to a referral hospital complex of the municipal and state health system assisting patients with pathologies of medium and high complexity, which also justifies these findings.

Another factor that may have contributed to a high $\mathrm{MRCl}$ in this study is the need of using individualized doses, off-label medications, and specific formulations. It is important to note that the same reasons leading to an increase in pharmacotherapy complexity can also lead to prescription errors in Pediatrics. ${ }^{7}$

A study carried out with elderly with CKD, which assessed hospital readmissions compared to pharmacotherapy complexity, also identified high $\mathrm{MRCl}$ values, which is justified by the fact that elderly also have high polypharmacy frequency, as well as pediatric patients with CKD. The authors of this study emphasize the importance of having more research studies on this topic to qualify patients' pharmacotherapy. ${ }^{19}$

The high complexity of pharmacotherapy was associated to the number of medications used by the patients with CKD in the outpatient clinic under study. This data corroborates the results of a study conducted with autistic adolescents and other studies with elderly patients with CKD, in which the number of medications was associated with higher $\mathrm{MRCl}$ values. Additionally, these studies assert that pharmacotherapy complexity is a useful tool to identify target patients for interventions in order to reduce complexity and optimize pharmacotherapy, ensuring control of the chronic disease. ${ }^{17,18,20}$

In this study, it was not possible to establish the relationship between high pharmacotherapy complexity and adherence to treatment, even though such relationship was found in the literature. ${ }^{21,22}$ The small sample of this study may justify this finding. The number of medications contributes to the increase 
in pharmacotherapy complexity, but it is not only related to that factor. Studies conducted with adult and elderly patients show that people with the same number of medications obtained different $\mathrm{MRCl}$ values and the same index value for different numbers of medications. ${ }^{23,24}$ This result was also found in this study, in which the same $\mathrm{MRCl}$ values were obtained for treatment with different numbers of medications, showing the importance of other factors in the calculation of the index, such as pharmaceutical form, frequency, and additional instructions. ${ }^{8}$

Regarding the medications used by the patients, the most used class was the cardiovascular medications, which corroborates with the fact that cardiovascular diseases, mainly hypertension, are associated with CKD, and the use of this class is recommended in the international guideline. ${ }^{3}$

Sodium bicarbonate was the most prescribed, and it was indicated for the treatment of metabolic acidosis, which is typical of CKD. The ATC does not include this indication for sodium bicarbonate, being classified as an antacid, irrigation solution and other intravenous indications. ${ }^{25}$ In addition, the oral use of sodium bicarbonate for metabolic acidosis is not established in Resolution 199/2006 the Collegiate Board, which regulates the use of medications of simplified notification and does not have an indication for the pediatric population. ${ }^{26}$ Accordingly, off-label use of this medication is a common practice in Pediatrics. ${ }^{27}$ Despite that, the guideline for CKD indicates sodium bicarbonate orally for metabolic acidosis, requiring an adaptation of the WHO's ATC and of the recommendations provided by the National Health Surveillance Agency. ${ }^{3}$

It is a worldwide trend to research and develop medicines following formulation principles centered on the patients' needs considering specificities in Pediatrics. ${ }^{28}$ A medication suitable for pediatric use must has a pharmaceutical form that provides variable dose release according to weight, height and age, physical and organoleptic characteristics that facilitate swallowing, an adequate device for measuring doses and providing a way of administration compatible with the pediatric age group for which it is intended. ${ }^{29}$

The need to manipulate (crush, break or dilute) powders and pills or to use of solutions is due to the lack of medicines registered for pediatric use. The manipulation or transformation of the pharmaceutical forms at home contributes to the increase in pharmacotherapy complexity, and the scarcity of research studies results in lack of important guidelines for the adaptation of medicines for Pediatrics in package inserts, which can contribute to lack of safety in pharmacotherapy. In addition, the caregiver or patient is required to be able to handle pharmaceutical forms at their homes, which makes adherence to treatment even more difficult and may reduce the effectiveness and safety of pharmacotherapy. ${ }^{30}$

That said, the management of pharmacotherapy in pediatric patients with high pharmacology complexity is extremely important, given the fact that pharmacists can intervene with caregivers, through verbal and written guidelines for the rational use of medications, prevention, identification and problem solving related to medications - and with the team, with proposals to provide a safer, more effective and less complex pharmacotherapy, as well as to increase treatment adherence. ${ }^{31}$

For pediatric pharmacotherapy to be the most indicated, effective, safe, and convenient, some attention is required when choosing the type of medication, adequate dose and age-appropriate formulation. ${ }^{30}$ It is important that these patients are assisted by specialized professionals who work in the management, assistance or development of specific medications for this population and that these professionals become aware of the particularities and specific protocols of pediatric patients. ${ }^{17,28,32}$

The present study has as limitations the collection of retrospective data, using secondary data, which may have caused bias in the analysis, due to the possibility of incomplete data in the medical records. The possibility of overestimating adherence due to social desirability bias was minimized in the study, since the pharmacist who applied the MAT did not conduct the appointment. The sample size and the fact that the study was performed only in an outpatient clinic in patients with a specific disease make it difficult to extrapolate the results to other pediatric groups. As this is the first study on $\mathrm{MRCl}$ in pediatric patients, as far as we know, we did not find any cutoff point for pediatric patients, and it was necessary to extrapolate the $\mathrm{MRCl}$ cutoff point for adults. ${ }^{13}$

On the other hand, it is worth mentioning that this study is innovative and that the identification of factors associated with high pharmacotherapy complexity can direct the prioritization of patients who must be followed-up by a clinical pharmacist for the rational use of medications and for a reduction in pharmacotherapy complexity.

\section{Conclusion}

The high medication regimen complexity was associated with the number of medicines used and was observed in most of the patients studied, highlighting the importance of assessing the $\mathrm{MRCl}$ in children to optimize pharmacotherapy and, consequently, paediatric patient's safety. Furthermore, the $\mathrm{MRCl}$ is an important element that can be used to screen patients for pharmacotherapy management, as well as to guide interventions in order to optimize the pharmacology of pediatric patients.

\section{Funding sources}

The research did not receive financing for its realization.

\section{Collaborators}

AMP, LPS and CC participated in the conception of the study, AMP, LPS, IBR and MRF in data collection, AMP, LPS and RCGV in data analysis, AMP, LPS, RCGV and CC in data interpretation and writing of the article, and PGA; MDS and CC critically reviewed the article. All the authors assume full responsibility for all the information contained in the paper.

\section{Acknowledgments}

We would like to thank all the professionals of the multiprofessional clinic for pediatric kidney disease, the clinical pharmacy and, especially, the resident pharmacists.

\section{Conflicts of interest statement}

The authors declare that there are no conflicts of interest regarding this article. 


\section{References}

1. Nóbrega VM, Silva ME de A, Fernandes LTB, et al. Chronic disease in childhood and adolescence: Continuity of care in the Health Care Network. Rev da Esc Enferm. 2017;51:1-8.

2. McDonald SP, Craig JC. Long-Term Survival of Children with End-Stage Renal Disease. N Engl J Med. 2004; 350(26):265462.

3. KDIGO. Clinical Practice Guideline for the Evaluation and Management of Chronic Kidney Disease. Kidney Int Suppl. 2012;

4. Schijvens AM, de Wildt SN, Schreuder MF. Pharmacokinetics in children with chronic kidney disease. Pediatr Nephrol. 2019; 35(7):1153-1172.

5. Soares CMB, Diniz JSS, Lima EM, et al. Doença renal crônica em pediatria- Programa Interdisciplinar de abordagem Pré-dialítica. Rev Med Minas Gerais. 2008;18(4 Supl 1):S90-7.

6. Wühl E, Schaefer F. Therapeutic strategies to slow chronic kidney disease progression. Pediatric Nephrology. 2008;23(5): 705-716.

7. Masnoon N, Shakib S, Kalisch-Ellett L, et al. What is polypharmacy? A systematic review of definitions. BMC Geriatrics. 2017. 17: 230. Published online 2017 Oct 10.

8. Melchiors AC, Correr CJ, Fernández-Llimos F. Tradução e validação para o português do Medication Regimen Complexity Index. Arq Bras Cardiol. 2007;89(4):210-8.

9. Abou-Karam N, Bradford C, Lor KB, et al. Medication regimen complexity and readmissions after hospitalization for heart failure, acute myocardial infarction, pneumonia, and chronic obstructive pulmonary disease. SAGE Open Med. 2016;19e2050312116632426.

10. Costa P, Rey L, Coelho H. Carência de preparações medicamentosas para uso em crianças no Brasil. J. Pediatr.2009;85(3):22935.

11. George J, Phun YT, Bailey MJ, et al. Development validation of the medication regimen complexity index. Ann Pharmacother. 2004;38(9):1369-76

12. Gomes M, Mastroianni G. Doença renal crônica: importância do diagnóstico precoce, encaminhamento imediato e abordagem interdisciplinar estruturada para melhora do desfecho em pacientes ainda não submetidos à diálise. J Bras Nefrol. 2011;33(1):93-108.

13. Dimatteo MR. Variations in Patients' Adherence to Medical Recommendations A Quantitative Review of 50 Years of Research. Medical care. 2004; 42(3):200-209.

14. Ferreira JM, Galato D, Melo AC. Medication regimen complexity in adults and the elderly in a primary healthcare setting: Determination of high and low complexities. Pharm Pract (Granada). 2015;13(4):659.

15. Contributo para a validação concorrente de uma medida de adesão aos tratamentos. Psicol Saúde e Doenças. 2001;2(2):81-100.

16. Hosmer Jr, David W., Stanley Lemeshow, et al. Sturdivant. Applied logistic regression. Vol. 398. John Wiley \& Sons, 2013.

17. Libby AM, Fish DN, Hosokawa PW, Linnebur SA, Metz KR,
Nair K V., et al. Patient-Level Medication Regimen Complexity Across Populations With Chronic Disease. Clin Ther. 2013; 35(4):385-398.

18. Parker K, Bull-Engelstad I, Aaseb $\varnothing$ W, et al. Medication regimen complexity and medication adherence in elderly patients with chronic kidney disease. Hemodial Int. 2019;23(3):333-42.

19. Tesfaye, Wubshet H., et al. "Medication regimen complexity and hospital readmission in older adults with chronic kidney disease." Annals of Pharmacotherapy 53.1 (2019): 28-34.

20. Barnet D, Hanks C, Li W, et al. Patient-Level Medication Regimen Complexity in an Adolescent and Adult Population with Autism Spectrum Disorders. Pharmacotherapy. 2019;39(6):636-644.

21. Morsh L, Dressler C, Schneider A, et al. Complexidade da farmacoterapia em idosos atendidos em uma farmácia básica no Sul do Brasil.Infarma Ciências Farmacêuticas. 2015;27:239247.

22. Silva A, Martins B, Adriano L, et al. Complexidade da farmacoterapia pós-transplante renal: influência na adesão ao tratamento. Rev. Eletr. Far. 2017;14(7):53-63.

23. Mansur N, Weiss A, Beloosesky Y. Looking beyond polypharmacy: quantification of medication regimen complexity in the elderly. Am J Geriatr Pharmacother.2012:10(4);223-9.

24. Balodiya S, Kamath A. Evaluation of Hospital Discharge Prescriptions in the Elderly and Younger Adults Using the Medication Regimen Complexity Index. Curr Drug Saf.2019:14(2);116-121.

25. WHO Collaborating Centre for Drug Statistics Methodology. ATC/DDD Index 2020. Available at https://www.whocc.no/ atc_ddd_index/. Accessed on Nov 08, 2019.

26. Agência Nacional de Vigilância Sanitária (Brasil). Resolução no 199 de 26 de outubro de 2006. Definição de medicamento de notificação simplificada. Diário Oficial da União 26 out 2006;Seção 1.

27. Loureiro C, Néri E, Dias H, et al. Uso de medicamentos off-label ou não licenciados para pediatria em hospital público brasileiro. Rev. Bras. Farm. Hosp. Serv. Saúde São Paulo. 2013; $4(1): 17-21$

28. Salunke S, Liu F, Batchelor H, et al. European Paediatric Formulation Initiative (EuPFI)-Formulating Ideas for Better Medicines for Children. AAPS PharmSciTech. 2017;18(2):257-62.

29. Van Riet-Nales DA, Schobben AFAM, Vromans $H$, et al. Safe and effective pharmacotherapy in infants and preschool children: Importance of formulation aspects. Archives of Disease in Childhood. 2016.101:662-9.

30. Marinho R, Cabral C. Estudo de Adaptações de Formulações Farmacêuticas em um Hospital Universitário Pediátrico. Rev. Bras. Farm. Hosp. Serv. Saúde São Paulo.2014;5(3):12-7.

31. Souza I, Nascimento M, Neves C, et al. Resultados clínicos do serviço de gerenciamento da terapia medicamentosa em um ambulatório de diabetes. Rev. Bras. Farm. Hosp. Serv. Saúde São Paulo.2017:8(3);19-24.

32. Manias E, Kinney S, Cranswick N, et al. Medication errors in hospitalised children. J Paediatr Child Health. 2014;50(1):717. 